\title{
Ophidascaris wangi sp. n. and O. najae (Gedoelst, 1916) (Ascaridida: Ascaridoidea) from snakes in China
}

\author{
Liang Li ${ }^{1}$, Yan-Ning Guo ${ }^{1}$, Jian $\mathbf{L i}^{2}$ and Lu-Ping Zhang ${ }^{1}$ \\ ${ }^{1}$ Key Laboratory of Animal Physiology, Biochemistry and Molecular Biology of Hebei Province, College of Life Science, Hebei \\ Normal University, Shijiazhuang, Hebei Province, China; \\ ${ }^{2}$ College of Animal Science and Technology, Guangxi University, Nanning, Guangxi Province, China
}

\begin{abstract}
Ophidascaris wangi sp. n. collected from the king rat snake Elaphe carinata (Günther) (Serpentes: Colubridae) in China is described using both light and scanning electron microscopy. The new species differs from its congeners in the presence of narrow lateral alae originating a short distance posterior to the base of the ventrolateral lips, its relatively long oesophagus (3.57-4.54 mm long, representing 6.6-7.6\% of body length), its short spicules (1.89-2.14 mm long, representing 3.9-4.3\% of body length), the number and arrangement of caudal papillae (49-57 pairs in total, arranged as follows: 43-51 pairs precloacal, 2 pairs joined paracloacal and 4 pairs postcloacal), the presence of a particular papilliform medioventral, postcloacal ornamentation and the morphology of the eggs and tip of the female tail. In addition, Ophidascaris najae (Gedoelst, 1916), collected from the king cobra Ophiophagus hannah Cantor (Serpentes: Elapidae) in China, is also redescribed. The morphology of the cervical papillae, labial denticles and phasmids of the female is described for the first time.
\end{abstract}

Keywords: Ascarididae, Nematoda, Elaphe carinata, morphology, taxonomy, Ophiophagus hannah

Species of Ophidascaris Baylis, 1921 (Nematoda: Ascaridida) commonly parasitise the digestive tract of various snakes (Baylis 1921, Johnston and Mawson 1942, Teixeira de Freitas 1967, 1968, Sprent 1988, Pinto et al. 2010). According to Sprent (1988), Ophidascaris includes over 30 nominal species reported worldwide. Of these, only five species, O. excavata Hsü et Hoeppli, 1931, O. filaria (Dujardin, 1845), O. hsuei Freitas, 1967, O. orientalis (Wang, 1965) and O. wui Freitas, 1967, have been reported from the Chinese mainland (Hsü and Hoeppli 1931, Wang 1965, Teixeira de Freitas 1968).

During a helminthological survey of reptiles in China, two species of ascaridid nematodes were collected from the king rat snake Elaphe carinata (Günther) and the king cobra Ophiophagus hannah Cantor, respectively. The results of detailed studies of these parasites, one of which represents a new species of Ophidascaris, are presented below.

\section{MATERIALS AND METHODS}

Live nematodes recovered from the digestive tract of the hosts were washed in physiological saline and then fixed in $80 \%$ hot ethanol. For light microscopical examination, the nematodes were cleared in lactophenol. Drawings were made with the aid of a Nikon microscope drawing attachment. For scanning electron microscopy (SEM), the specimens were fixed in cold $4 \%$ formaldehyde solution, post-fixed in $1 \%$ osmium tetroxide, dehydrated via an ethanol series and acetone, and then criticalpoint dried. The specimens were coated with gold and examined using a Hitachi S-570 scanning electron microscope at an accelerating voltage of $15 \mathrm{kV}$. Measurements (the range, followed by the mean in parentheses) are given in millimetres unless otherwise stated. Voucher specimens were deposited at the College of Life Science, Hebei Normal University, Hebei Province, P. R. China (HBNU) and the Institute of Parasitology, Biology Centre of the Academy of Sciences of the Czech Republic in České Budějovice (IPCAS).

\section{RESULTS}

Ophidascaris wangi sp. $\mathrm{n}$.

Figs. 1-3

General. Medium to large, whitish nematodes. Posterior part of body distinctly wider than anterior part, especially in females. Cuticle with fine transverse striations. Anterior extremity with 3 roughly oval lips, approximately equal in size, with deep postlabial grooves and promiment lateral membraneous flanges (Figs. 1A,C, 2A,B). Distal part of each lip with small, obtusely triangular, medioapical notch (Figs. 2A,B, 3D). Dorsal lip with pair of large double papillae (Figs. 1A, 2B); ventrolateral lips each with single double papilla, small papilla and amphid (Figs. 1C, 2A). Interlabia well developed, triangular, about 2/5 length of lips (Figs. 1B, 2A, 3A). Lips with distal ridge armed with acuminate denticles (Figs. $1 \mathrm{~A}-\mathrm{C}$, 

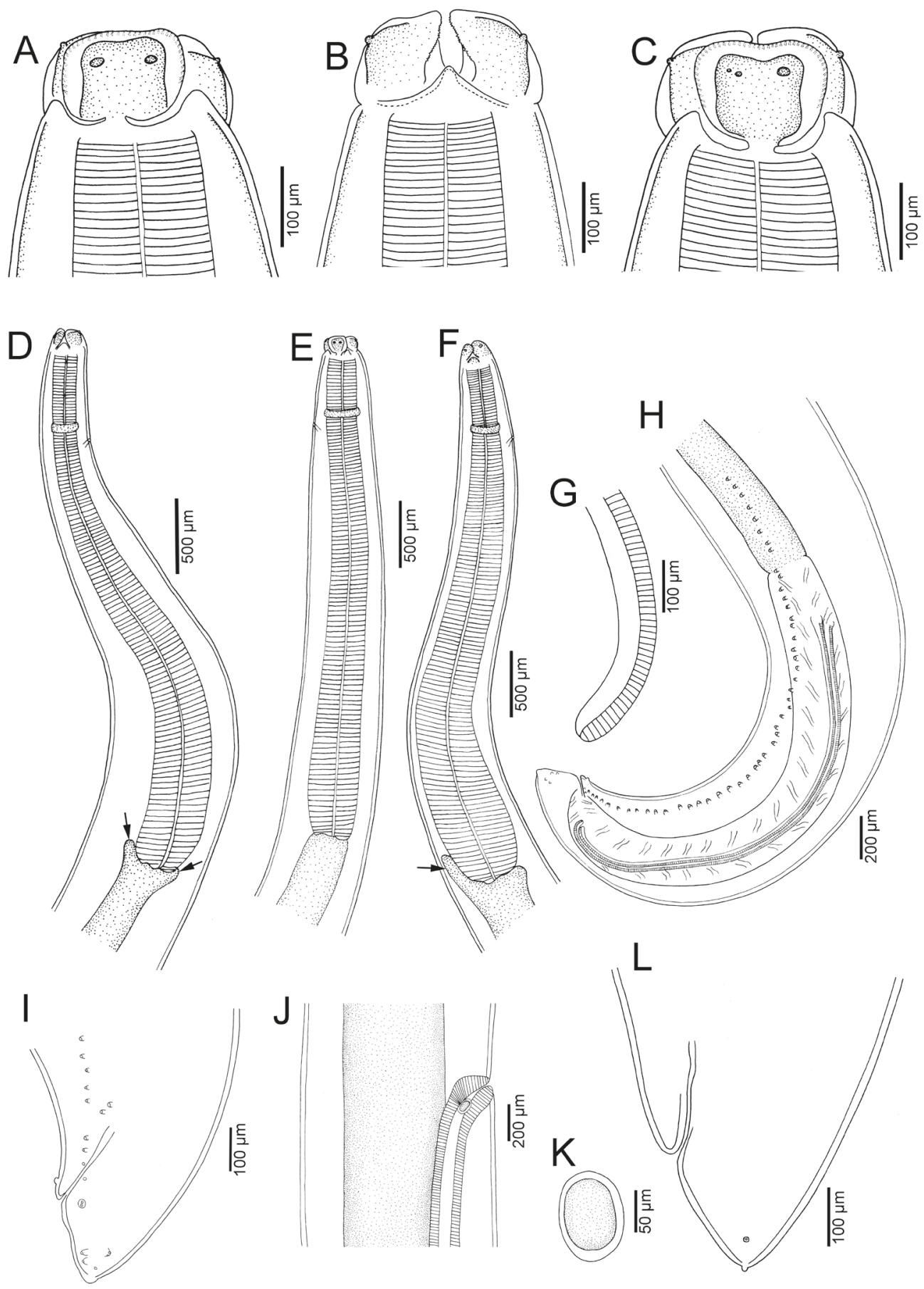

Fig. 1. Ophidascaris wangi sp. n. from Elaphe carinata, China. A - anterior region of male, dorsal view; B, C - cephalic end of female, ventral and ventrolateral view; D-F - anterior region of body of male (showing morphological variability in the caecumlike structure - arrows); G - distal end of spicule, lateral view; $\mathbf{H}$ - posterior end of male, lateral view; $\mathbf{I}$ - tail of male, lateral view; $\mathbf{J}$ - region of vulva; $\mathbf{K}$ - egg; $\mathbf{L}$ - posterior end of female, lateral view.

2A,B, 3D,E). Pair of small, submedial pores present symmetrically on each lip just external to ridge (Fig. 2A,B). Cervical alae narrow, starting from short distance posterior to base of ventrolateral lips and extending posterior to oesophagus; caudal alae absent (Fig. 3A,B). Cervical papillae situated laterally, undivided, just posterior to excretory pore (Fig. 3A,B). Oesophagus long, narrow, slightly broader posteriorly than anteriorly. Ventriculus absent. Intestinal caecum-like structure (or a fold of intestine) sometimes present (Fig. 1D-F). Nerve-ring at about $15 \%$ of oesophageal length. Excretory pore just posterior to nerve-ring (Fig. 3A,C). Tail of both sexes conical, tip unornamented (Figs. 1H,I,L, 2E,G,H). 

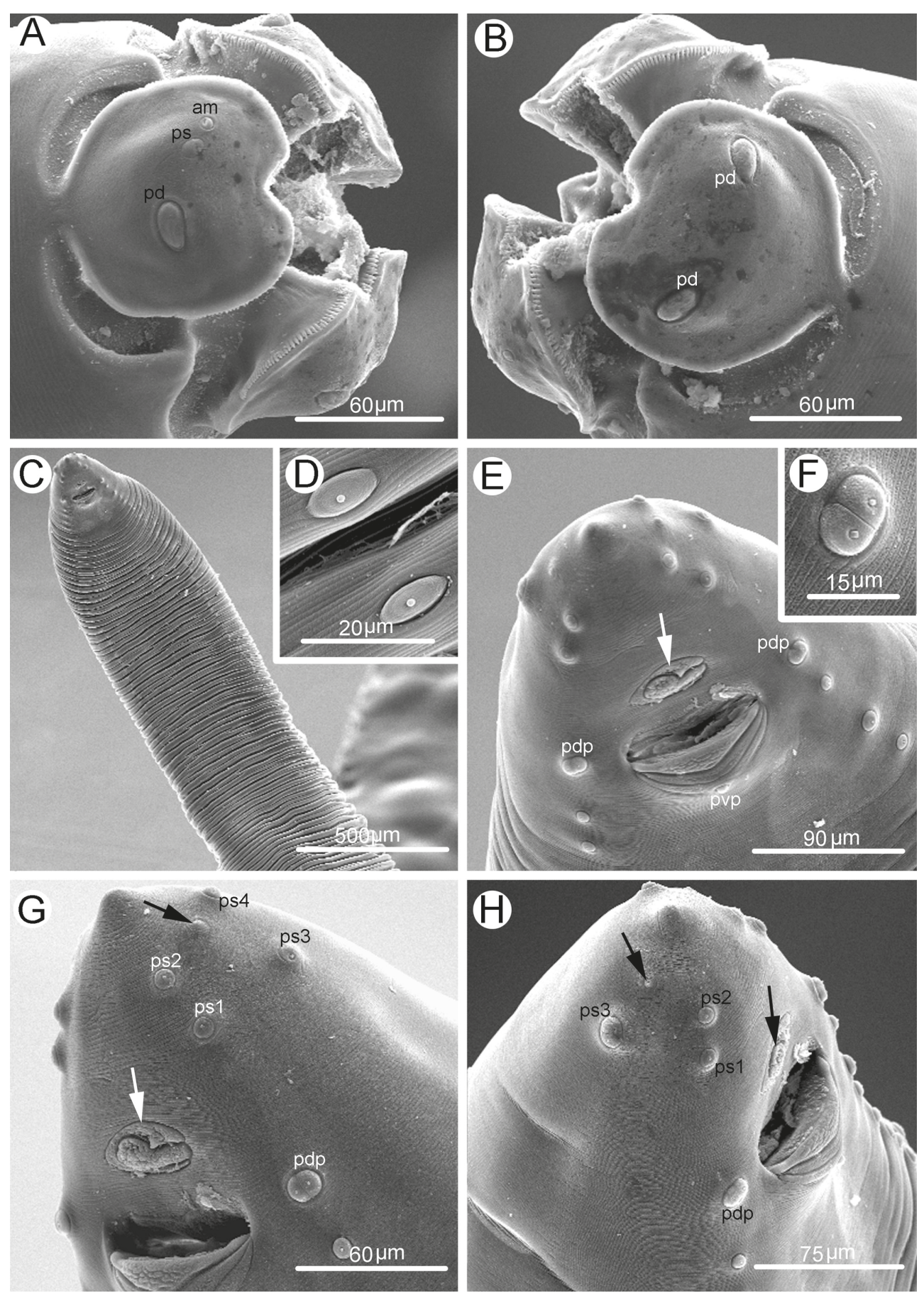

Fig. 2. Scanning electron micrographs of Ophidascaris wangi sp. n. from Elaphe carinata, China, male. A - cephalic extremity, ventrolateral view; B - cephalic extremity, dorsal view; C - posterior end of body, ventral view; D - detail of precloacal papillae; $\mathbf{E}$ - tail, ventral view (medioventral, postcloacal ornamentation arrowed); $\mathbf{F}$ - detail of paracloacal double papilla; $\mathbf{G}, \mathbf{H}$ - tail, ventrolateral view (phasmid and medio-ventral, postcloacal ornamentation arrowed). Abbreviations: am - amphid; pd - double papilla; pdp - paracloacal double papilla; ps - single papilla; ps1, ps2 - first and second pair of ventrolateral postcloacal papillae, respectively; ps3, ps4 - third a fourth pair of dorsolateral postcloacal papillae; pvp - medio-ventral precloacal papilla.

Male (based on 4 mature specimens): Body 48-50 (49) long; maximum width $0.78-0.87$ (0.83). Dorsal and ventrolateral lips almost equal in size, $0.11-0.13(0.12)$ long, $0.15-0.17(0.16)$ wide. Interlabia 0.05-0.07 (0.06) long, $0.17-0.18$ (0.18) wide. Oesophagus 3.57-3.81 (3.73) long, 0.44-0.49 (0.46) in maximum width, representing $7.4-7.6 \%$ (7.6\%) of body length. Nerve-ring and excretory pore $0.63-0.68(0.66)$ and $0.68-0.75(0.71)$, respectively, from anterior extremity. Posterior end of body curves ventrally. Spicules robust, alate, of almost equal length, 

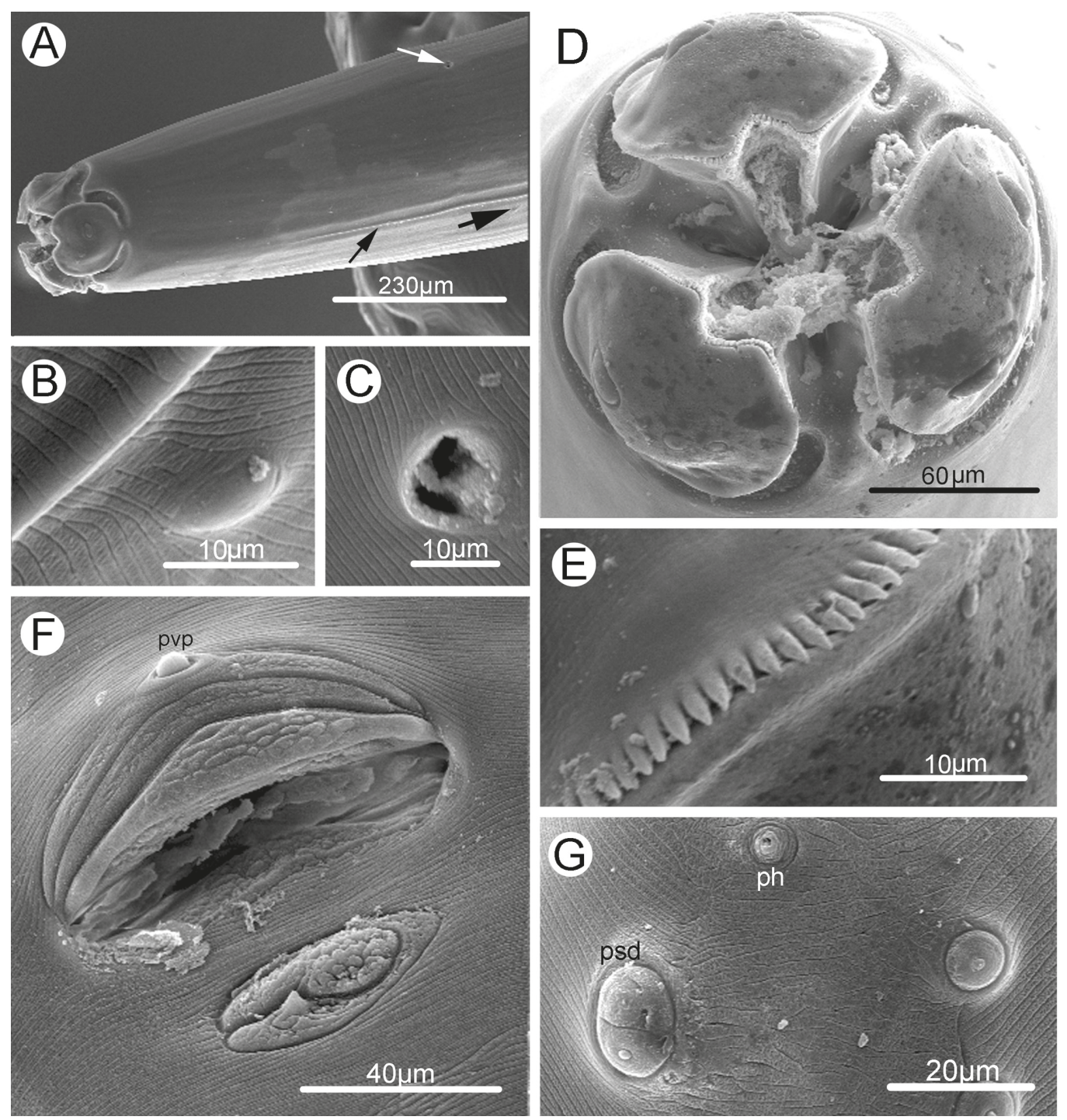

Fig. 3. Scanning electron micrographs of Ophidascaris wangi sp. n. from Elaphe carinata, China, male. A - anterior region of body, ventrolateral view (cervical papilla indicated by large black arrow, cervical ala indicated by small black arrow and excretory pore indicated by white arrow); $\mathbf{B}$ - magnified image of cervical papilla (undivided) and cervical ala; $\mathbf{C}$ - detail of excretory pore; $\mathbf{D}$ - cephalic extremity, apical view; $\mathbf{E}$ - detail of denticles; $\mathbf{F}$ - detail of cloacal region, ventral view; $\mathbf{G}$ - detail of postcloacal papillae and phasmid. Abbreviations: ph - phasmid; psd - postcloacal double papilla; pvp - medioventral precloacal papilla.

rounded at distal end, 1.89-2.14 (2.06) long, representing $3.9-4.3 \%(4.2 \%)$ of body length (Fig. $1 \mathrm{G}, \mathrm{H})$. Gubernaculum absent. Caudal papillae $49-57$ pairs in total, arranged as follows: 43-51 pairs precloacal, 2 pairs joined paracloacal and 4 pairs postcloacal; latter arranged as 2 pairs dorsolateral (sometimes joined together) and 2 pairs ventrolateral (Figs. 1H,I, 2C-H, 3G). Single medioventral precloacal papilla and papilliform medioventral postcloacal ornamentation present (Figs. 2E,G,H, 3F). Tail 0.180.20 (0.19) long, with blunt conical tip (Figs. 1I, 2E,G,H). Small lateral phasmids present (Figs. 1I, 2E,G,H, 3G).

Female (based on 6 gravid specimens): Body 61-65 (63) long; maximum width 1.05-1.10 (1.06). Dorsal and ventrolateral lips almost equal in size, $0.12-0.13(0.13)$ long, 0.15-0.18 (0.17) wide. Interlabia 0.05-0.07 (0.06) long, 0.16-0.19 (0.18) wide. Oesophagus 4.05-4.54 (4.35) long, 0.49-0.52 (0.50) in maximum width, representing $6.6-7.3 \%(6.9 \%)$ of body length. Nerve-ring and excretory pore $0.68-0.78(0.75)$ and $0.78-0.87(0.83)$, respectively, from anterior extremity. Vulva slit-like, situated posterior to mid-body, 35.0-38.4 (36.2) from anterior extremity, at $56.7-60.2 \%(57.3 \%)$ of body length (Fig. 1J). Vagina muscular, directed posteriorly from vulva. Uterus with two parallel branches. Eggs oval, with almost smooth shell, 0.08-0.10 (0.09) × 0.07-0.08 (0.08) $(\mathrm{n}=24)$ (Fig. 1K). Tail 0.20-0.23 (0.21) long, with small button-like tip (Fig. 1L). Small lateral phasmids present, at base of tail tip (Fig. 1L).

Ty pe host: King rat snake Elaphe carinata (Günther) (Serpentes: Colubridae). 
Table 1. Morphological and morphometric differences between Ophidascaris wangi sp. n. and the other species of the 'obconica' group of Sprent (1988) (measurements in $\mathrm{mm}$ ).

\begin{tabular}{|c|c|c|c|c|c|c|c|c|c|c|}
\hline Species & IC & $\mathrm{CA}$ & $\mathrm{OL}$ & SL & OL/BL (\%) & SL/BL (\%) & $\mathrm{TF}$ & $\mathrm{SE}$ & $\mathrm{PV}$ & PP (pairs) \\
\hline $\begin{array}{l}\text { O. ashi } \\
\text { Sprent, } 1988\end{array}$ & absent & absent & - & $3.0-4.5$ & - & $4.7-5.6$ & absent & WCP & - & - \\
\hline $\begin{array}{l}\text { O. excavata } \\
\text { Hsü et Hoeppli, } 1931\end{array}$ & present & absent & - & - & $4.5-5.6$ & - & - & - & absent & $50-58$ \\
\hline $\begin{array}{l}\text { O. mombasica } \\
\text { Baylis, } 1921\end{array}$ & absent & - & $2.7-3.0$ & - & $3.5-4.6$ & - & - & - & - & $32-35$ \\
\hline $\begin{array}{l}\text { O. obconica } \\
\text { (Baird, 1860) }\end{array}$ & absent & - & $2.0-3.0$ & 2.48 & about 5.0 & - & absent & WCP & - & - \\
\hline $\begin{array}{l}\text { O. piscatori } \\
\text { Soota et Chaturvedi, } 1970\end{array}$ & absent & - & - & - & $3.7-5.0$ & - & - & WCP & - & - \\
\hline $\begin{array}{l}\text { O. pyrrhus } \\
\text { Johnston et Mawson, } 1942\end{array}$ & absent & absent & - & - & - & $5.6-7.2$ & absent & - & absent & - \\
\hline $\begin{array}{l}\text { O. solenopoion } \\
\text { Chabaud, } 1960\end{array}$ & absent & absent & - & - & - & - & absent & - & absent & - \\
\hline $\begin{array}{l}\text { O. trichuriformis } \\
\text { Vaz, } 1935\end{array}$ & absent & - & - & - & $4.5-5.6$ & - & - & - & absent & - \\
\hline O. wangi sp. n. & $\begin{array}{l}\text { present in some } \\
\text { individuals }\end{array}$ & present & $3.6-4.5$ & $1.9-2.1$ & $6.6-7.6$ & $3.9-4.3$ & $\begin{array}{l}\text { button-like } \\
\text { tip present }\end{array}$ & smooth & present & $43-51$ \\
\hline
\end{tabular}

Abbreviations: IC - intestinal caecum-like structure; CA - cervical alae; OL - length of oesophagus; SL - length of spicules; BL - length of body; $\mathrm{TF}$ - tail tip of female; SE - shell of egg; PV - medioventral, postcloacal ornamentation; PP - precloacal papillae; WCP - with conspicuous pits. The morphometric data of Ophidascaris spp. is based on Baylis (1921), Hsü and Hoeppli (1931), Johnston and Mawson (1942), Teixeira de Freitas (1968) and Sprent (1988).

Type locality: Nanning $\left(108^{\circ} 22^{\prime} \mathrm{E} ; 22^{\circ} 48^{\prime} \mathrm{N}\right)$, Guangxi Province, China; May 2013.

Site of infection: Stomach.

Prevalence and intensity: Unknown.

Type specimens: Holotype: male (HBNU-R14004L); allotype: female (HBNU-R14005L); paratypes: 2 males, 4 females (HBNU-R14006L), 1 male, 1 female (IPCAS N-1062).

E ty mology: The species is named for Pu-Qin Wang (Fujian Normal University, China) for his major contribution to the knowledge of the ascaridoid nematode fauna in China.

Remarks. The gross morphology of the present ascaridid specimens collected from Elaphe carinata, especially the morphology of the lips, the presence of interlabia, the presence or absence of intestinal caecum-like structure, the absence of ventriculus and the uterus with two branches clearly indicates they should belong to Ophidascaris. Sprent (1988) reviewed Ophidascaris and divided it into five morphological groups based on the morphology of adults, host and geographical distribution.

With a trichuriform body, lips distinctly wider than long and being parasitic in a colubrid snake in Asia, the new species appears to belong to the 'obconica' group of Sprent (1988), which currently includes the following eight species; O. ashi Sprent, 1988, O. excavata, O. mombasica Baylis, 1921, O. obconica (Baird, 1860), O. piscatori Soota et Chaturvedi, 1970, O. pyrrhus Johnston et Mawson, 1942, O. solenopoion Chabaud, 1960 and O. trichuriformis Vaz, 1935, (see Sprent 1988). The details of the morphological and morphometric differences between the new species and all its congeners in the 'obconica' group of Sprent (1988), are summarised in Table 1.
To our knowledge, only $O$. najae has been reported collected from the king rat snake Elaphe carinata. However, $O$. wangi sp. n. can be easily distinguished from $O$. najae by the different morphology of lips, tip of the tail and the medioventral, postcloacal ornamentation, much shorter spicules (1.89-2.14 mm, representing 3.9-4.3\% of body length in the new species vs 3.30-5.83 mm, representing $6.5-9.0 \%$ of body length in $O$. najae) and the almost smooth eggs ( vs eggs coarsely pitted in the latter) (for data on O. najae see Sprent 1988 and the present srudy below).

In recent years, two more species of Ophidascaris have been described, i.e. O. durissus Panizzutti, dos Santos, Vicente, Muniz-Pereira et Pinto, 2003 from the rattlesnake Crotalus durissus Linnaeus (Serpentes: Viperidae) and $O$. tuberculatum Siqueira, Panizzutti, Muniz-Pereira et Pinto, 2005 from the pit viper Bothrops jararaca Wied (Serpentes: Viperidae), both from Brazil (Panizzutti et al. 2003, Siqueira et al. 2005). However, according to the description of O. durissus given by Panizzutti et al. (2003), this species cannot be regarded as belonging to Ophidascaris because of the absence of interlabia and appears more likely to be a species of Hexametra Travassos, 1920. Siqueira et al. (2005) described $O$. tuberculatum, which should belong to the 'arndti' group of Sprent (1988), but, unfortunately, these authors did not mention the work of Sprent (1988) in their paper, and thus the morphological justification of $O$. tuberculatum in relation to other species of Ophidascaris is poor. Furthermore, the species O. arndti Sprehn, 1929, which also occurs in the Bothrops spp. from Brazil, was ignored. Based on the description of O. tuberculatum by Siqueira et al. (2005) and O. arndti 
by Sprent (1988), O. tuberculatum and O. arndti seem to be identical. Consequently, $O$. tuberculatum may well be a synonym of $O$. arndti.

\section{Ophidascaris najae (Gedoelst, 1916)}

Figs. 4-6

General. Large, whitish nematodes. Posterior part of body slightly wider than anterior part; maximum width at about mid-body. Cuticle with fine transverse striations. Anterior extremity with 3 more or less quadrangular lips, approximately equal in size, with deep postlabial grooves and promiment lateral membraneous flanges (Figs. 4A,B, 5A, 6C). Distal part of each lip with small, obtusely triangular, medioapical notch (Figs. 5A, 6C). Dorsal lip with pair of large double papillae (Figs. 4A, 5E); ventrolateral lips each with single double papilla, small papilla and amphid (Figs. 4B, 5D, 6C). Interlabia well developed, triangular, about 2/5 length of lips (Figs. 4D, 5C, 6A). Lips with distal ridge armed with acuminate denticles (Figs. 4A,B,D, 5D,E,H, 6C). Pair of small, submedial pores present symmetrically on each lip just external to ridge (Fig. 6C). Cervical alae prominent, extend from well posterior to base of ventrolateral lips to posterior to oesophagus; caudal alae absent (Figs. 5A, 6A). Cervical papillae situated laterally, bifid, just posterior to excretory pore (Fig. 5B). Oesophagus long, slightly broader posteriorly than anteriorly. Ventriculus absent. Intestinal caecum-like structure (or fold of intestine) absent (Fig. 4C). Nerve-ring at $19-27 \%$ of oesophageal length (Fig. 4C). Excretory pore just posterior to nerve-ring (Figs. 4C, 6A,B). Tail of both sexes conical; tip unornamented (Figs. 4I,J, 5F, 6D,E).

Male (based on 6 mature specimens): Body 43-67 (59) long; maximum width 0.58-1.12 (0.92). Dorsal and ventrolateral lips almost equal in size, $0.15-0.17(0.16)$ long, 0.13-0.17 (0.15) wide. Interlabia 0.05-0.08 (0.07) long, $0.14-0.20(0.18)$ wide. Oesophagus 2.86-4.29 (3.69) long, 0.22-0.34 (0.30) in maximum width, representing $5.5-6.6 \%(6.2 \%)$ of body length. Nerve-ring and excretory pore $0.76-0.83(0.79)$ and $0.90-0.97(0.93)$, respectively, from anterior extremity. Spicules robust, alate, subequal, rounded at distal end, 3.30-5.83 (4.61) long, representing $6.5-9.0 \%$ (7.8\%) of body length (Fig. 4F,H). Gubernaculum absent. Caudal papillae 43-65 pairs in total, arranged as follows: $37-59$ pairs precloacal, 2 pairs joined paracloacal and 4 pairs postcloacal; latter arranged as 2 pairs dorsolateral (sometimes joined together) and 2 pairs ventrolateral (Figs. 4G,I, 6D-F). Single medioventral precloacal papilla and postcloacal rough area present (Figs, 4G, 6D,G). Tail 0.15-0.22 (0.19) long, with digitiform tip. Small lateral phasmids present (Figs. 4I, 6D,E).

Female (based on 10 gravid specimens): Body 26-105 (67) long; maximum width 0.63-1.28 (0.86). Dorsal and ventrolateral lips almost equal in size, $0.12-0.22(0.16)$ long, $0.11-0.22(0.16)$ wide. Interlabia $0.05-0.09$ (0.07) long, $0.15-0.25$ (0.19) wide. Oesophagus 2.86-4.64
(3.89) long, 0.27-0.39 (0.32) in maximum width, representing $4.4-11.0 \%$ (5.8\% of body length. Nerve ring and excretory pore $0.51-0.92(0.78)$ and $0.78-1.12(1.02)$, respectively, from anterior extremity, respectively. Vulva situated near or posterior to middle of body, 17.9-56.0 (35.6) from anterior extremity, at $47-61 \%$ (53\%) of body length. Vagina muscular, directed posteriorly from vulva (Fig. 4E). Uterus with two parallel branches. Eggs relatively small, oval to almost spherical, with finely pitted shell, 0.07-0.08 (0.075) × 0.06-0.08 (0.07) $(\mathrm{n}=24)$ (Fig. 4K). Tail 0.20-0.37 (0.25) long, with digitiform tip (Figs. 4J, 5G). Small lateral phasmids at base of tail tip (Figs. 4J, 5F,G).

Type host: Naja nigricollis (Reinhardt) (Serpentes: Elapidae).

Type locality: Leopoldville, Zaire.

Host and locality of the present material: King cobra Ophiophagus hannah Cantor (Serpentes: Elapidae); Fujian Province, China; 6 May 1977.

Site of infection: Stomach.

Prevalence and intensity: Unknown.

Voucher specimens: 7 males, 30 females (HBNUR14007L), 1 male, 1 female (IPCAS N-1063).

Remarks. Sprent (1988) redescribed Ophidascaris najae based on the types and additional specimens parasitic in various elapid and colubrid snakes from Africa and Asia, including material collected from Ophiophagus hannah. The morphology and measurements of the present material collected from $O$. hannah in China agree well with the redescription of this species given by Sprent (1988), including the morphology of the lips, body size, the length of oesophagus and spicules, the number and arrangement of the precloacal and paracloacal papillae, the presence of a single medioventral precloacal papilla and a postcloacal rough area, the position of the vulva, the size of the eggs and the shape of the tail in both sexes. We have, therefore, no hesitation in considering our present specimens to be conspecific with $O$. najae. Sprent (1988) stated that there were $4-5$ pairs postcloacal papillae (arranged as 2 pairs dorsoateral and 2-3 pairs ventrolateral) in his specimens. However, we only observed 3-4 pairs (arranged as 1-2 pairs dorsolateral and 2 pairs ventrolateral) in our material. Sprent (1988) also reported the presence of one or two intestinal caecum-like structures in some specimens of $O$. najae, but we did not find this structure in our specimens. We consider these morphological differences to represent intraspecific variability, possibly owing to the different hosts or geographical locations. The detailed morphology of the cervical papillae, labial denticles and the phasmids in female were revealed herein for the first time.

According to Sprent (1988), Ophidascaris macrospicula Mozgovoy et Romanova, 1956 was also collected from the king cobra O. hannah. However, Sprent (1988) speculated that $O$. macrospicula was probably identical 

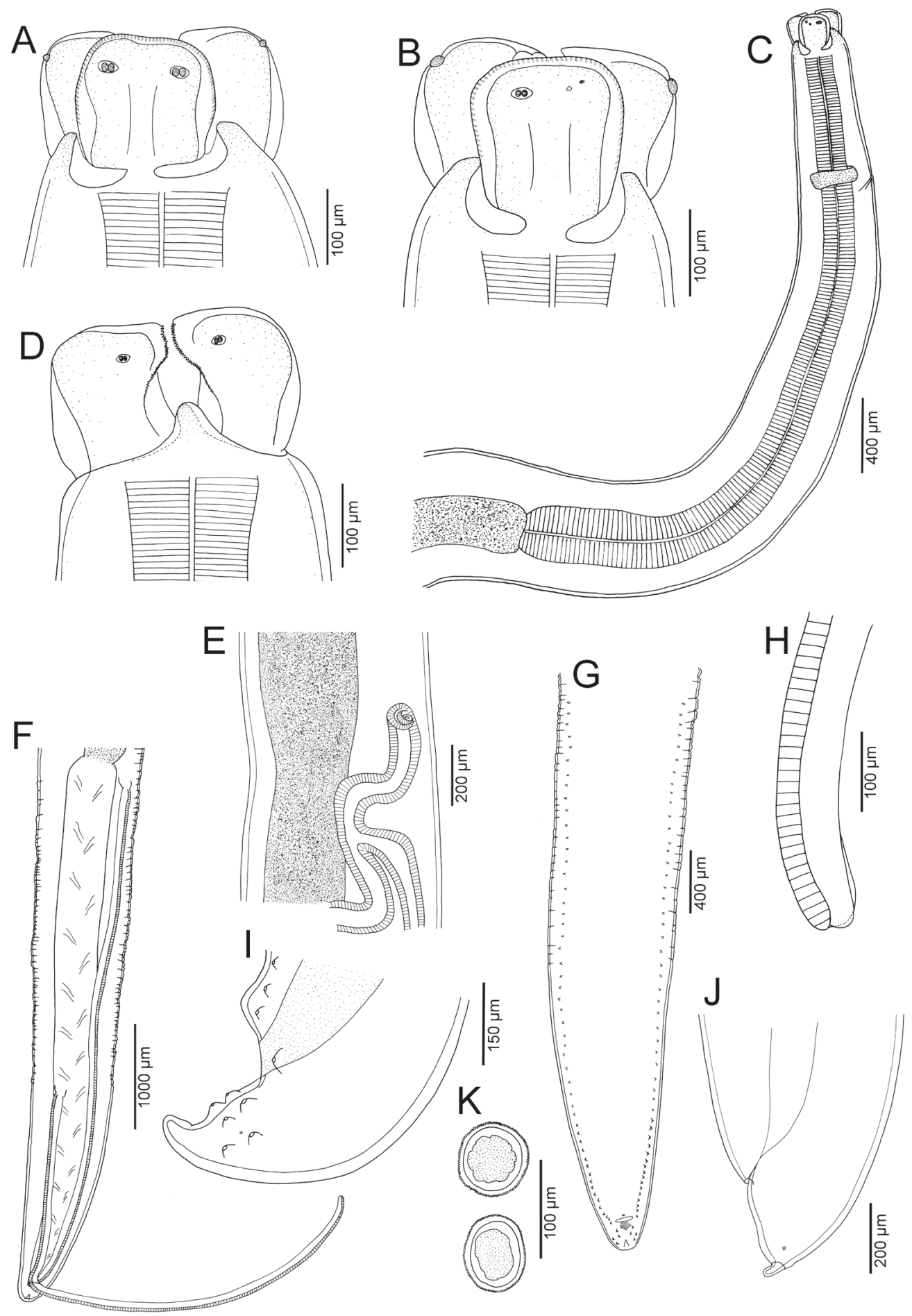

Fig. 4. Ophidascaris najae (Gedoelst, 1916) from Ophiophagus hannah, China. A, B, D - cephalic end of female, dorsal, ventrolateral and ventral view, respectively; $\mathbf{C}$ - anterior region of female, ventrolateral view; $\mathbf{E}$ - region of vulva; $\mathbf{F}$ - posterior end of male, ventral view (showing spicules); $\mathbf{G}$ - posterior end of male, ventral view (showing caudal papillae); $\mathbf{H}$ - distal end of spicule, lateral view; $\mathbf{I}$ - tail of male, lateral view; $\mathbf{J}$ - posterior end of female, lateral view; $\mathbf{K}$ - eggs.

with $O$. najae and may represent a synonym of $O$. najae. Sprent (1988) considered that O. agkistrodontis Wang, 1979 collected from Agkistrodon acutus (Günther) (Serpentes: Viperidae) in China should belong to the 'najae' group of Sprent (1988). However, he overlooked this species without interlabia; thus, it seems likely that we cannot allocate it to Ophidascaris. In addition, because there was no the female specimen in the original description and we do not known the detailed characters of vulva and uterus, which are of generic importance for differ- 


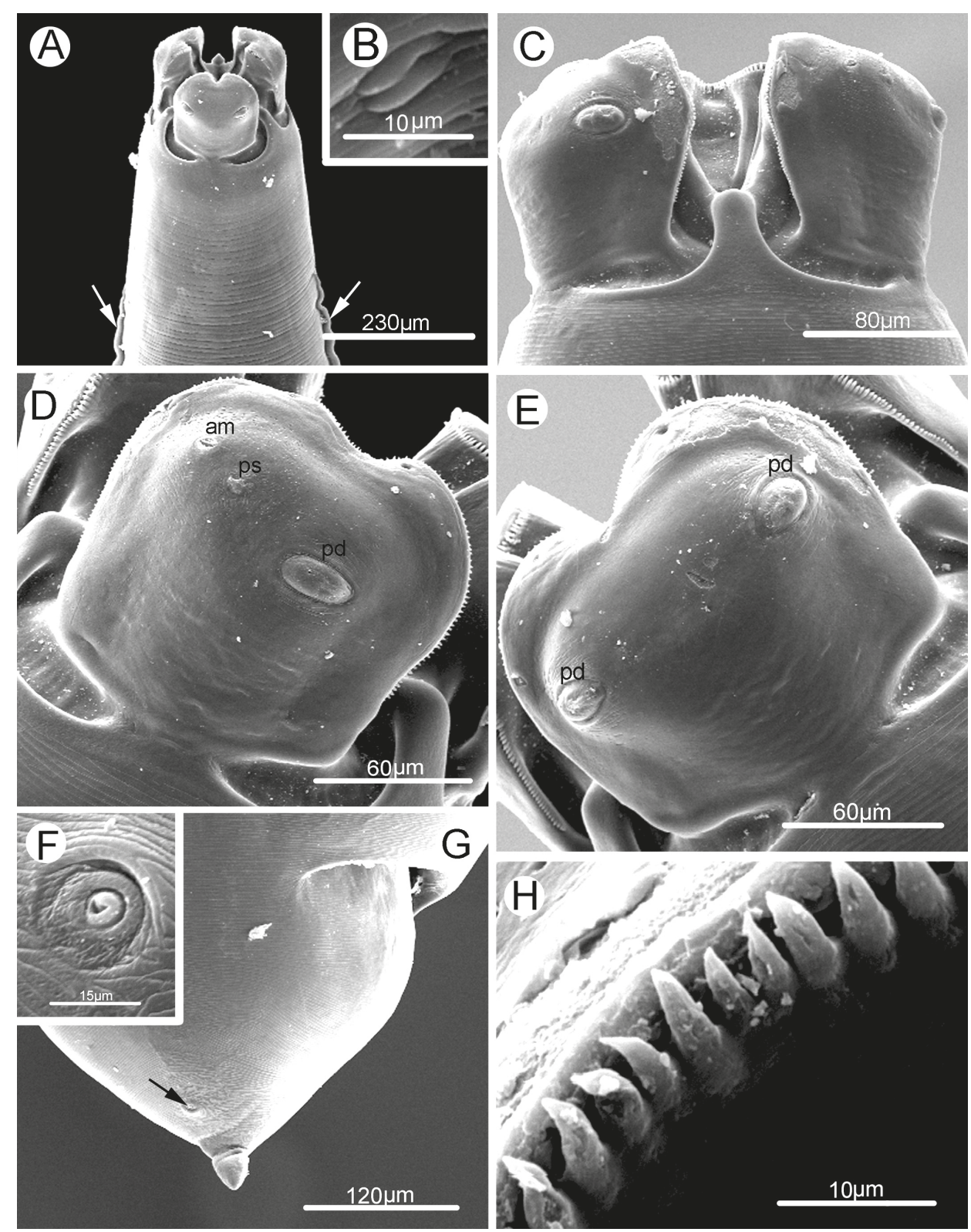

Fig. 5. Scanning electron micrographs of Ophidascaris najae (Gedoelst, 1916) from Ophiophagus hannah, China. A - anterior region of male, dorsal view (cervical alae arrowed); $\mathbf{B}$ - detail of cervical papilla (bifid); $\mathbf{C}$ - cephalic extremity of male, lateral view; D - ventrolateral lip; $\mathbf{E}$ - dorsal lip; F - detail of phasmid of female; $\mathbf{G}$ - posterior end of female, lateral view (phasmid arrowed); $\mathbf{H}$ - detail of denticles. Abbreviations: am - amphid; pd - double papilla; ps - single papilla.

entiation of Hexametra and Polydelphis Dujardin, 1845. Ophidascaris agkistrodontis should be considered as incertae sedis.

\section{DISCUSSION}

Baylis (1921) established Ophidascaris and designated $O$. filaria as its type species. Subsequently, Teixeira de Freitas (1968) and Sprent (1988) reviewed this genus. However, mainly because of the many inadequate species descriptions of Ophidascaris and occasionally the use of unsuitable specific criteria, the taxonomic status of many species remains somewhat confused. In Ophidas- caris, the differential features such as the shape of lips, the absence or presence of cervical alae or intestinal caecum-like structure, the length of the oesophagus and spicules, the morphology of the tail and eggs, the position of the vulva, the absence or presence and its morphology of medioventral precloacal or postcloacal ornamentation, and the number and arrangement of caudal papillae, are commonly used for recognising different species (Baylis 1921, Johnston and Mawson 1942, Teixeira de Freitas 1967, 1968, Sprent 1988, Pinto et al. 2010).

Most of the above mentioned characteristics are of specific significance also in other ascaridoid genera, such as 

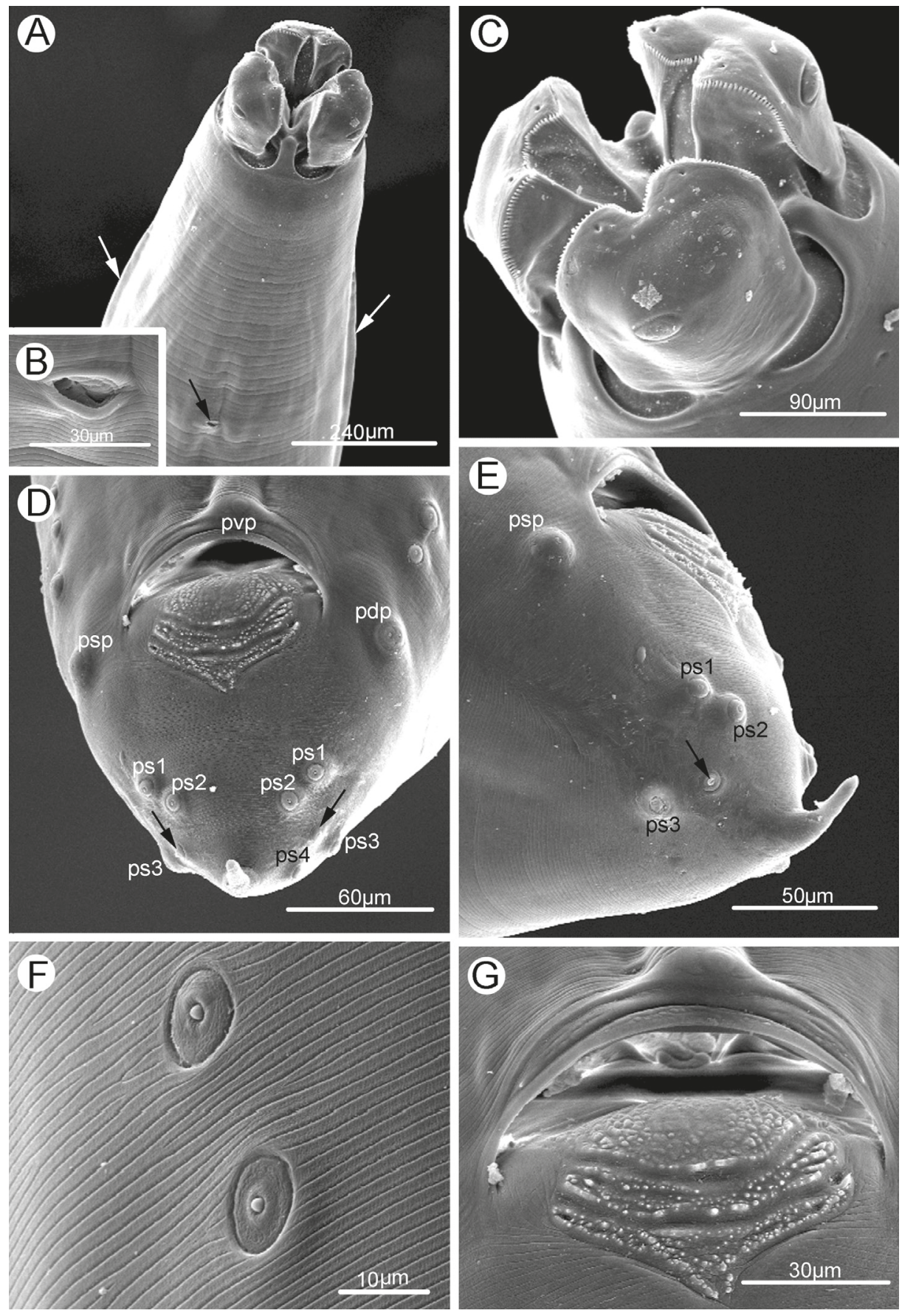

Fig. 6. Scanning electron micrographs of Ophidascaris najae (Gedoelst, 1916) from Ophiophagus hannah, China. A - anterior region of male, ventral view (cervical alae and excretory pore arrowed); $\mathbf{B}$ - detail of excretory pore; $\mathbf{C}$ - cephalic extremity of male, subapical view; D, E - posterior end of male, ventral and lateral view (phasmids arrowed), respectively; $\mathbf{F}$ - detail of precloacal papillae; G - detail of cloacal region, ventral view. Abbreviations: pdp - paracloacal double papilla; psp - paracloacal single papilla; pvp - medio-ventral precloacal papilla; ps1, ps2 - first and second pair of ventrolateral postcloacal papillae, respectively; ps3, ps 4 - third and fourth pair of dorsolateral postcloacal papillae, respectively.

Contracaecum Railliet et Henry, 1912, Dujardinascaris Baylis, 1947, Goezia Zeder, 1800, Hysterothylacium Ward et Magath, 1917, Pseudanisakis Layman et Borovkova, 1926, Mawsonascaris Sprent, 1990 and Raphidascaris Railliet et Henry, 1915 (see Smith 1984, Fagerholm et Gibson 1987, Bruce 1990, Sprent 1977, 1990, Li et al.
2012, 2013). However, the absence or presence of intestinal caecum-like structure, which is commonly used as a generic criterion in some ascaridoid nematodes, is quite unreliable as the differentiating feature in Ophidascaris. This feature is rather variable within a species, as has been observed in $O$. najae, O. excavata and $O$. wangi sp. 
n. (see Sprent 1988; present study). This situation also occurs in Dichelyne pleuronectidis (Yamaguti, 1935) (Ascaridida: Cucullanidae) (see Li et al. 2014).

Regarding the length of the oesophagus and spicules, this may be somewhat variable within a species depending partly on the body size and age of the worm, but it has been regarded to be a valuable character for identification of ascaridoid nematodes, especially when used together with the ratio to the body length. The number and arrangement of paracloacal and postcloacal papillae is considerable stable in Ophidascaris spp.: two pairs paracloacal in total, in most cases jointed together; four pairs postcloacal in total, arranged as 2 pairs dorsolateral (sometimes joined together to form one) and 2 pairs ventrolateral, which is not of specific significance. There are usually numerous pairs of precloacal papillae situated in single row in Ophidascaris spp. and number is highly variable within a species in some cases (e.g. 35-59 pairs in $O$. najae, 37-52 pairs in $O$. wui, 38-51 pairs in $O$. solenopoion). It indicates that caution must be taken when this character is used to differentiate species.

In conclusion, it is clear that most of the diagnostic characters used by Baylis (1921), Johnston and Mawson (1942), Teixeira de Freitas $(1967,1968)$ and Sprent (1988) as specific criteria are not in question, although the validity of some species of this genus appear to be questionable. A taxonomic revision of Ophidascaris, based on detailed morphological (preferably by SEM), life history and molecular studies of individual species, is quite necessary.

Acknowledgements. This study was supported by the China Postdoctoral Science Foundation (No. 2014T70227). Postdoctoral Research Projects Merit Subsidy of Human Resources and Social Security Department of Hebei Province, and the Natural Science Foundation and Biology Postdoctoral Programme of Hebei Normal University (Nos. L2010B13 and 111008).

\section{REFERENCES}

BAylis H.A. 1921: On the classification of the Ascaridae. II. The Polydelphis group; with some account of other ascarids parasitic in snakes. Parasitology 12: 411-426.

BRuce N.L. 1990: Hysterothylacium Ward and Magath, 1917, and Ichthyascaris $\mathrm{Wu}, 1949$, ascaridoid nematodes from Australian demersal fishes. Mem. Queensl. Mus. 28: 389-426.

Fagerholm H.P., Gibson D.I. 1987: A redescription of the pinniped parasite Contracaecum ogmorhini (Nematoda, Ascaridoidea), with an assessment of its antiboreal circumpolar distribution. Zool. Scr. 16: 19-24.

Hsü H.F., Hoeppli R. 1931: Parasitic nematodes mostly from snakes collected in China. Nat. Med. J. China 17: 567-588.

Johnston T.H., Mawson P.M. 1942: The Gallard collection of parasitic nematodes in the Australian Museum. Rec. Aust. Mus. 21: 110-115.

Li L., Du L.-Q., Xu Z., Guo Y.-N., Wang S.-X., Zhang L.-P. 2014: Morphological variability and molecular characterisation of Dichelyne (Cucullanellus) pleuronectidis (Yamaguti, 1935) (Ascaridida: Cucullanidae) from the flatfish Pleuronichthys cornutus (Temminck \& Schlegel) (Pleuronectiformes: Pleuronectidae) in the East China Sea. Syst. Parasitol. 87: 87-98.

Li L., LiU Y.-Y., LiU B.-C., Zhang L.-P. 2012: Morphological and molecular evidence for a new species of the genus Raphidascaris (Nematoda: Anisakidae) from marine fishes from the South China Sea. Parasitol. Res. 110: 1473-1479.

Li L., Zhang L.-P., LiU Y.-Y. 2013: Hysterothylacium simile n. sp. (Nematoda: Raphidascarididae) and H. aduncum (Rudolphi, 1802) from marine fishes in the Bohai and Yellow Sea, China, with comments on the record of $H$. paralichthydis (Yamaguti, 1941) in the Chinese waters. Syst. Parasitol. 84: 57-69.

Panizzutti M.M.H., dos Santos L.C., Vicente J.J., MunizPereira L.C., Pinto R.M. 2003: Ophidascaris durissus sp.

Received 25 March 2014 nov. (Nematoda Ascarididae) parasitizing Crotalus durissus Linnaeus (Ophidia, Viperidae) in Brazil. Rev. Bras. Zool. 20: 9-11.

Pinto R.M., Muniz-Pereira L.C., Panizzutti M.M.H., NoRONHA, D. 2010: Nematode parasites of the neotropical rattlesnake, Crotalus durissus Linnaeus, 1758 (Ophidia, Viperidae) from Brazil: new records and general aspects. Neotrop. Helminthol. 4: 137-147.

Smith J.D. 1984: Taxonomy of Raphidascaris spp. (Nematoda, Anisakidae) of fishes, with a redescription of $R$. acus (Bloch, 1772). Can. J. Zool. 62: 685-694.

Siqueira L.R., Panizzutti M.H.M., Muniz-Pereira L.C., Pinto R.M. 2005: Description of a new ascaridoid parasite of Bothrops jararaca Wied (Reptilia, Ophidia) in Brazil. Rev. Bras. Zool. 22: 587-590.

Sprent J.F.A. 1977: Ascaridoid nematodes of amphibians and reptiles: Dujardinascaris. J. Helminthol. 51: 253-287.

Sprent J.F.A. 1988: Ascaridoid nematodes of amphibians and reptiles: Ophidascaris Baylis, 1920. Syst. Parasitol. 11: 165213.

Sprent J.F.A. 1990: Some ascaridoid nematodes of fishes: Paranisakis and Mawsonascaris n. g. Syst. Parasitol. 15: 41-63.

Teixeira de Freitas J.F. 1967: Nota sôbre o gênero Ophidascaris Baylis, 1921 (Nematoda, Ascaridoidea). Atas Soc. Biol. Rio de Janeiro 11: 27-30.

Teixeira de Freitas J.F. 1968: Revisâo do gênero Ophidascaris Baylis, 1921 (Nematoda, Ascaridoidea). Mem. Inst. Oswaldo Cruz 66: 1-83.

WANG P.C. 1965: Notes on some nematodes of the suborder Ascaridata from Fukien, China. Acta Parasitol. Sin. 2: 366-379. (In Chinese, English summary.)

Accepted 18 June 2014 